$* * *$

\title{
Federico Martocci, La politica cultural del Partido Socialista en el Territorio Nacional de La Pampa: dispositivos y prácticas de intervención de sus dirigentes e intelectuales (1913-1919), Santa Rosa: Universidad Nacional de La Pampa, 2015, 272 pp.
}

Tomando el término de Raymond Williams, quien así hacía referencia no sólo a las zonas rurales, sino a la totalidad de las actividades económicas y vitales de una región determinada, la pregunta por la circulación de las propuestas culturales del Partido Socialista en el countryside argentino estructura el reciente libro de Federico Martocci. Preocupado por las condiciones y posibilidades que habria encontrado el socialismo para promover su mensaje e instalar su repertorio de prácticas culturales en un espacio donde la condición de Territorio Nacional restringía la participación en la política formal, Martocci nos brinda un detallado estudio del esfuerzo por construir un socialismo pampeano a la vez que nos permite pensar las particularidades que tuvo esta construcción politica por fuera de las principales ciudades del país.

Aunque el socialismo argentino tuvo mayor peso en las zonas urbanas, el PS intentó en estos años trascender esa condición para integrar a su proyecto político a los trabajadores rurales. Es en este sentido que La política cultural... ofrece una reconstrucción interesante entre las propuestas para el ámbito rural propias de los principales dirigentes del partido y las condiciones particulares que asumió la construcción de un socialismo en el territorio pampeano.

La primera parte del libro compone un estudio minucioso de las prácticas que permitieron al socialismo crecer en la región. Allí podemos ver de qué manera el ideal en torno a la difusión de la cultura letrada, al traducirse en prácticas concretas, permitió a través de la circulación de las publicaciones y el dictado de conferencias canalizar funciones diferentes que se complementaban en la construcción política.

La menor importancia que cobraba en el territorio la práctica de la política formal hizo que los socialistas pudieran dedicar mayor energía a la tarea de formar ciudadanos. Los periódicos, principalmente Germinal, ocuparon en esa tarea una labor fundamental llevando las ideas del PS a las diferentes localidades de la región, pero también cumplieron un rol importante informando sobre las conferencias y cursos que se dictaban en las bibliotecas y dando lugar a los escritos de lectores, articulando así entre los distintos sectores que adherian al socialismo territoriano.

La tarea cumplida por los periódicos se completó con la organización de las bibliotecas y el dictado de conferencias. El autor destaca que, a pesar del enorme esfuerzo que suponía sostener su funcionamiento, el territorio pampeano vio nacer en estos años una gran cantidad de bibliotecas socia- 
listas, si comparamos con otras regiones del país. El dictado de conferencias resulta interesante a su vez porque combinó la difusión de la propaganda clásica del PS con una adaptación a contenidos que fueran de interés a los agricultores de la zona, motivando, en muchos casos, el traslado desde el campo hacia las localidades para atender a las disertaciones de referentes locales.

Esta reconstrucción del esfuerzo por unir el territorio a través de los proyectos culturales impulsados por los centros partidarios nos acerca entonces a una experiencia compleja en la que fue necesario convivir con contradicciones particulares (denostar a los almacenes por ser el lugar donde se conseguía la bebida, aunque allí también se reunieran los agricultores y fueran un ámbito por el que circulaban los periódicos) y que se nutrió de las luchas y demandas específicas de la región, generando conocimiento sobre las condiciones de la producción y difundiendo reclamos e informaciones sobre las legislaciones que interesaban a los arrendatarios, a la vez que esto servía para impulsar nuevas demandas.

Cabe destacar también la originalidad de la segunda parte del libro dedicada a reconstruir las trayectorias, en clave biográfica, de dos figuras singulares del socialismo pampeano como lo fueron el agricultor Antonio Buira y el crítico literario y escritor Salomón Wapnir.

La trayectoria de Antonio Buira, quien se integró al socialismo desde el prestigio que le confería su participación en distintas luchas agrarias, nos permite conocer de cerca algunos de los rasgos distintivos del socialismo pampeano con respecto a los sectores más vinculados a las luchas urbanas. Su perfil de agricultor le permitió insertarse dentro del repertorio de actividades culturales desde conocimientos especificos que podian ser valorados por otros productores, ya fuera con respecto a cuestiones técnicas de la producción, como también en lo referido a la defensa de las condiciones de los arrendatarios. Esta condición de líder socialista y agrario iluminó una trayectoria de gran valor dentro de la construcción política del partido, como se puede ver en el hecho de que se le ofreciera la candidatura para ocupar una banca en el Concejo Municipal de Santa Rosa en 1916. Por otro lado, sus críticas a la dirigencia partidaria y sus posicionamientos frente a la Revolución Rusa conforman una expresión interesante de las tensiones que en estos años llevarian a la escisión de "los internacionalistas", como también una demostración de la autonomía con la que Buira asumía su militancia dentro de las filas socialistas.

El caso de Salomón Wapnir resulta más particular aún, ya que es el caso de un intelectual fuera del centro del país, que sin embargo pudo insertarse en las redes intelectuales de Buenos Aires, y también en las redes antiimperialistas trasnacionales como demuestran sus fluidos intercambios con dirigentes del APRA peruano. Estas características lo transformaron en un referente indiscutido de la tarea cultural del socialismo territoriano.

De esta manera el libro de Martocci, fruto de su tesis doctoral, nos acerca, a través de un conjunto muy sólido y novedoso de fuentes, a una experiencia 
muchas veces soslayada en la bibliografia sobre el socialismo argentino. La conformación de centros partidarios por fuera del área urbana, con una composición de dirigentes donde no predominaban los abogados y médicos y con una extensión mucho mayor por abarcar, otorgaron rasgos y desafios distintos a los socialistas de La Pampa en la tarea de elevar material y moralmente al pueblo. Tomando como eje articulador la práctica cultural, la lectura de este libro resulta un aporte novedoso para el conocimiento de las condiciones en las que el socialismo de la primera mitad del siglo XX intentó constituirse como una fuerza nacional.

Javier Guiamet (IDIHCS-UNLP)

$$
* * *
$$

\section{Maria Cristina Tortti, Che, una revista de la "nueva izquierda" (1960-1961), Buenos Aires: Cedinci, 2013, 366 pp.}

La aparición del peronismo y su desarrollo a mediados del siglo XX en Argentina configuró un escenario signado por el desencuentro entre la izquierda y el movimiento obrero. En adelante, el eje central de la actividad teórica y política del heterogéneo espectro de izquierdas giró en torno a la cuestión de qué hacer con el peronismo. En este sentido, el trabajo de M.C. Tortti estuvo abocado al estudio del surgimiento de la llamada Nueva Izquierda (NI) hacia fines de los años 50, entendida como un espacio de confluencia de agrupamientos con diversas trayectorias e ideologías (provenientes del peronismo, la izquierda, el nacionalismo y el catolicismo), que comparten, según la autora, un lenguaje y un estilo común en un clima de malestar a nivel político que tendía al cuestionamiento de las formas de autoridad y representación. El foco de sus investigaciones se centró en la crisis desatada al interior del Partido Socialista (PS) a partir del desarrollo de un sector que buscó renovar al "viejo" PS antiperonista y pro Revolución Libertadora para reencontrarlo con los trabajadores.

El presente libro se encuentra en sintonía con sus anteriores trabajos y está centrado en el estudio de la revista Che, cuya aparición es entendida como una experiencia "ilustrativa del clima que se vivía en algunos ámbitos del socialismo y el comunismo" (p. 9). La autora pone a disposición del público una antología de textos publicados en la revista, que cuenta con un total de 27 números editados entre 1960 y 1961. Ordenados temáticamente, se destacan artículos de política nacional, situación económico-social, Cuba, universidad e internacionales, entre otros; incluye también entrevistas, notas de humor, cine, teatro y deportes. La antología se acompaña de un estudio preliminar en el que Tortti, por un lado, da cuenta de los procesos generales a partir de los cuales es posible comprender el surgimiento de la NI; y, por el otro, presenta el caso específico de la revista Che como un capítulo significativo en la erosión del prestigio de la izquierda tradicional 